\title{
A HARPA DE PEDAIS, SEU PROVÁVEL PRIMEIRO \\ REPERTÓRIO E ALGUMAS CONSIDERAÇÓES \\ SOBRE MADAME DE GENLIS
}

\author{
Felipe Faglioni \\ Universidade de São Paulo-SP \\ Email:felipe847@bol.com.br
}

\section{Resumo:}

Esse artigo discorre a respeito da harpa de pedais e daquele que, possivelmente, teria sido seu repertório ao longo das primeiras décadas do século XVIII, período anterior à primeira publicação conhecida de composiçôes originalmente escritas para o instrumento. Pensando a respeito da música que poderia ter sido executada por intérpretes do instrumento no citado período, o texto foca-se na prática improvisatória dos prelúdios e também na apropriação, por parte dos harpistas, do repertório originalmente destinado a outros instrumentos, como o cravo ou o pianoforte. Nesse contexto, o artigo trata também da figura de Madame de Genlis (1746-1830), importante harpista do século XVIII, bem como de algumas de suas opiniôes sobre a técnica e as possibilidades da harpa de pedais utilizada na época.

Palavras-chave: Harpa de pedais. Século XVIII. Repertório. Prelúdios. Madame de Genlis.

The pedal harp, its probable first repertoire and some considerations on Madame de Genlis

\section{Abstract:}

This paper discourses about the pedal harp and what would have possibly been its repertoire through the first decades of the $18^{\text {th }}$ century, a period before the first known publication of original compositions for the instrument. Thinking about the music that could have been performed by the harpists 
of that time, the text focuses on the improvisational practice of preludes and also on the harpist's appropriation of a repertoire originally composed for other instruments, like the harpsichord or the pianoforte. Within this context, the paper also discourses about the figure of Madame de Genlis (1746$1830)$, an important harpist from the $18^{\text {th }}$ century, and on her opinions about the technique and possibilities of the pedal harp used during that time.

Key words: Pedal harp. $18^{\text {th }}$ Century. Repertoire. Preludes. Madame de Genlis.

Tendo sido inventada em fins do século XVII, a harpa de pedais parece, já durante seus primeiros anos de existência, ter agradado grande parte do público que a ouvia e ganhado cada vez mais popularidade durante as primeiras décadas do século XVIII.

A consequência desse crescimento em meio ao gosto do público alcançaria seu ápice na Paris da segunda metade do mesmo século, quando a grande quantidade de pessoas interessadas em tocar e ouvir a harpa de pedais mostrava-se clara através do alto número de intérpretes, professores e construtores do instrumento que havia na cidade.

Não é, portanto, estranho que a primeira coleção de peças escritas originalmente para a harpa de pedais, "Six Sonates pour harpe, Opus I", de Christian Hochbrücker (1733-1812), tenha sido publicada em Paris, no ano de 1762.

Considerando-se que o instrumento tenha sido inventado por Jacob Hochbrücker (1673-1763), em 1697 (existe certa controvérsia a respeito da identidade de seu real inventor bem como da data de sua invenção), percebe-se que mais de meio século teria de passar até que surgisse a publicação de um repertório original para o instrumento.

Infelizmente, não se pode dizer com exatidão qual o repertório que os harpistas executavam durante os primeiros anos do século XVIII. No entanto, é claro que havia algum considerado próprio entre os intérpretes, já que esses davam concertos públicos e privados e, portanto, deveriam possuir um repertório específico que pudesse ser executado propriamente ao instrumento. 
Durante pouco mais de seus primeiros cem anos de existência a harpa de pedais foi construída com um mecanismo diferente daquele das harpas modernas que, apesar de parecido, dava características distintas ao instrumento, influenciando diretamente a música que poderia ser por ele executada. $\mathrm{O}$ primeiro mecanismo de pedais, denominado de ação-simples, permitia ao instrumento alterar a afinação de suas cordas apenas uma vez, diferentemente do mecanismo moderno, dito de ação-dupla, patenteado por Sébastien Érard no início do século XIX, que permite duas alteraçóes nas mesmas. A diferença entre esses dois mecanismos de pedais trouxe diversas distinçóes entre as harpas nas quais eram utilizados, sendo que as principais delas sejam talvez as limitaçóes harmônicas presentes no instrumento de ação-simples que podia tocar numa quantidade relativamente menor de tonalidades e tinha suas possibilidades modulatórias reduzidas em relação ao de ação-dupla que mais tarde viria a substituí-lo completamente. Portanto, as possibilidades musicais da harpa de pedais estavam, no século XVIII, completamente atreladas ao mecanismo de ação-simples e as suas características.

Através do conhecimento da harpa da época e de algumas declaraçóes que chegaram até os dias de hoje é possível supor qual teria sido o primeiro repertório do instrumento. Além da possibilidade de composiçóes do período que por motivos diversos náo chegaram a ser publicadas e se perderam, muito provavelmente fariam parte do repertório dos harpistas transcriçóes de peças originalmente escritas para outros instrumentos (como o cravo, por exemplo, ou mesmo para outros tipos de harpa), além de música improvisada pelos intérpretes.

Se existentes, composiçóes originais para o instrumento poderiam ser excelentes exemplos do pensamento harpístico do início do século XVIII. Provavelmente, junto ao novo instrumento de pedais uma técnica para executá-lo estaria sendo elaborada e desenvolvida pelos executantes e as possibilidades dessa nova harpa vieram a gerar uma linguagem idiomática para o instrumento, linguagem essa que chega à segunda metade do século como padrão na música para harpa, aceita pelos compositores, intérpretes e ouvintes.

É provável que o improviso junto ao instrumento tenha sido algo importante e recorrente entre os harpistas, especialmente na época em que ainda não havia um repertório signi- 
ficativo para o instrumento. Não é possível afirmar que peças de longa duração teriam sido improvisadas por harpistas em público, mas o conhecimento e a técnica necessária para se ter a capacidade de executar pequenas peças, introduçóes, variaçóes ou algo do gênero parece ter sido considerado importante na então formação dos harpistas.

Georges-Adam Goeppfert (1727?-1809?), harpista alemão, na França mais comumente chamado de Gaiffre, foi o primeiro músico a tocar uma harpa de pedais em Paris, em 1749. Não se sabe o que Gaiffre teria executado nessas apresentaçóes, mas, segundo France Vernillat (1969, p.162) o periódico da época Le Mercure afirma que o músico havia sido fortemente aplaudido.

Madame de Genlis (1746-1830), que viria a se tornar a mais célebre aluna de Gaiffre faz afirmaçóes no primeiro capítulo de seu "Nouvelle Méthode pour la harpe"(1811) que podem, de certa forma, esclarecer o tipo de música tocada por seu professor:

Gaiffre foi durante muitos anos o único harpista em Paris; ele era bom construtor e grande músico, mas tocava mal a Harpa ou, para melhor dizer, ele nấo a tocava, ele preludiava tocando acordes de uma excelente harmonia, mas sem passagens brilhantes e sem execuçáo [...]. Gaiffre posicionava bem o corpo e as mãos, mas não tendo nunca executado nada além de arpejos ele não tinha ideia de dedilhados. (GENLIS, 1811, p.2).

Tratando ou não de forma depreciativa a técnica e a música feita por seu mestre, Genlis é clara ao dizer que Gaiffre "preludiava" e que nunca executava algo que fosse além de arpejos.

Essa afirmação não certifica que Gaiffre não tocava nada além do que diz a autora, mas permite a ideia de que o músico na maioria das vezes improvisasse, e que pequenos prelúdios e música utilizando constantemente as mesmas figuraçóes seriam a maior parte do executado pelo harpista.

Madame de Genlis (1811, p.2) também afirma que Gaiffre foi durante muito tempo um dos músicos mais requisitados como professor de harpa em Paris. Isso pode ter se dado também pelo fato de Gaiffre ter sido por alguns anos o único harpista da cidade, como diz Genlis, mas mesmo assim não é possível negar que o harpista possuísse uma grande quantidade de admiradores. A partir disso é possível se imaginar que a música que Gaiffre costumava tocar, mesmo não sendo profunda ou brilhante, bastava 
para causar admiração em seu público. Logo, o tipo de improvisação que o músico provavelmente utilizava com frequência pode ter sido, durante certo tempo, considerado suficiente por parte daqueles interessados na música tocada à harpa.

Uma das formas de improviso praticadas na harpa era o prelúdio. "Preludiar" (do francês préluder), significava improvisar prelúdios, trechos musicais que, na maioria das vezes, serviam como introdução a peças maiores. Um prelúdio, nesse caso, teria como função principal apresentar e confirmar a tonalidade da composição que seria tocada logo após a introdução. A técnica para se preludiar envolvia, portanto, o conhecimento de harmonia, das tonalidades, cadências, modulaçóes e de suas peculiaridades, bem como a aplicação desse conhecimento junto ao instrumento musical escolhido.

Toussant Bordet (c.1710-c.1775), no seu "Méthode raisonnée pour apprendre la musique", de 1755, define o prelúdio como:

[...] um canto de capricho que se compóe de improviso. É dessa espécie de prelúdio que um homem hábil se serve para fazer brilhar seu gênio sobre o instrumento que domina, percorrendo com arte os diferentes tons dos dois Modos, e terminando esse canto voluntário em seu primeiro tom sem quase perceber-se que se afastou do mesmo. Esse tipo de prelúdio é feito para a diversão do intérprete ou quando se vai executar qualquer peça musical: nesse último caso, deve ser observado em qual Tom e Modo essa peça é composta, a fim de realizar seu prelúdio nesse tom; esse prelúdio, consequentemente, serve de preparaçáo e de introdução a essa obra. (BORDET, 1755, p.15).

Por ser uma prática comum não só na música envolvendo a harpa, mas também outros instrumentos, vários manuais sobre o assunto foram escritos durante o século XVIII e início do XIX. São alguns exemplos importantes o "L'art de préluder, Opus VII" para flauta transversal e outros instrumentos, de Jacques-Martin Hotteterre (1674-1763), publicado em 1719, e também "The art of preluding, op. 300", para piano, de Carl Czerny (1791-1857), de 1833.

A distância entre as datas de publicação dos dois documentos citados acima mostra que durante mais de um século o prelúdio foi visto como um aspecto importante na performance musical dos instrumentistas. Em relação à harpa de pedais, mesmo quan- 
do a mesma já contava com um repertório próprio, a partir da segunda metade do século XVIII, os prelúdios continuaram a fazer parte de seu universo musical.

Um dos melhores exemplos de manuais exemplificando a técnica do prelúdio aplicada à harpa é o "L’art de préluder sur la har$p e$ ” de Louis Charles Ragué (c.1760-1793). Publicado em 1786, o livro mostra maneiras de se improvisar prelúdios nas tonalidades possíveis ao instrumento.

Mesmo que essencialmente frutos da criação momentânea do intérprete, os prelúdios eram, por vezes, também escritos nas partituras, dispensando assim a improvisaçáo do intérprete mas possuindo o mesmo caráter e exercendo a mesma função junto à composição.

Muitos métodos para harpa de pedais tratam, mesmo que não especificamente, desse tipo de composiçáo, sendo que em vários deles é possível encontrar exemplos de prelúdios em diversas tonalidades, servindo como pequena peça introdutória ou como exercício técnico.

As figuras seguintes mostram alguns desses prelúdios escritos, de diferentes compositores:
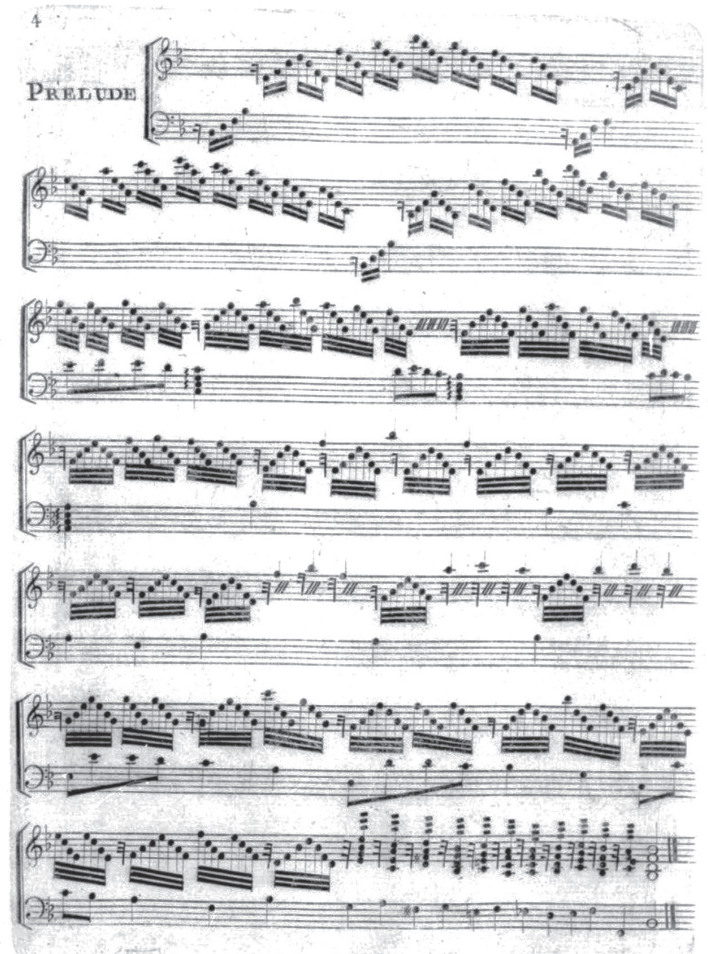

Fig. 1: Prelúdio em si bemol maior, de Henri Petrini (1775-1800?) (PETRINI, 1779, p. 4). 


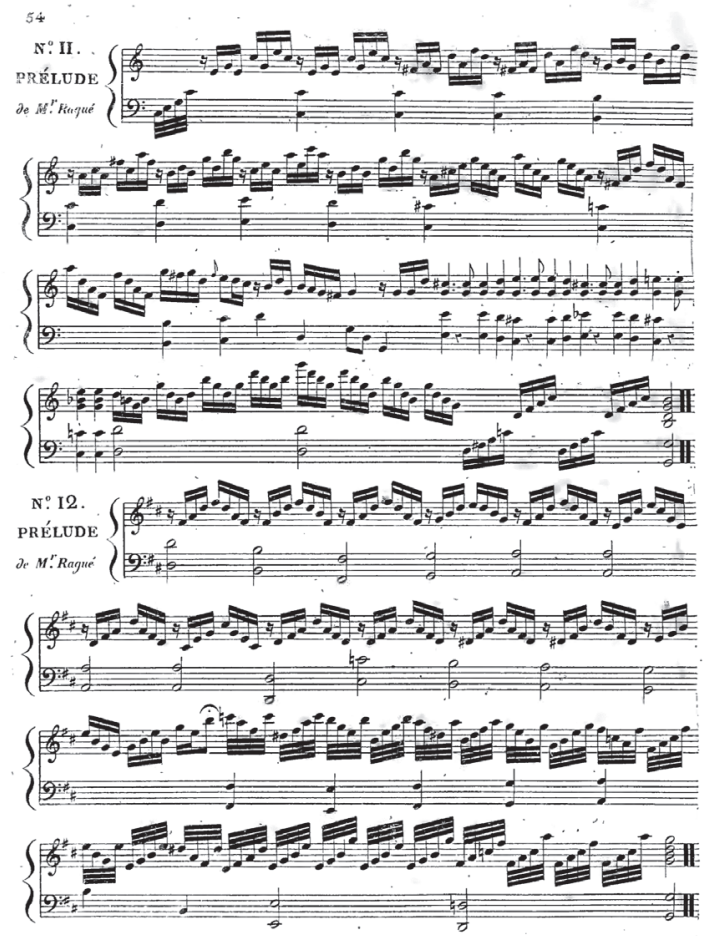

Fig. 2: Dois prelúdios de Ragué, apresentados no "Méthode de Harpe" de George Cousineau (COUSINEAU, 1803, p. 54).

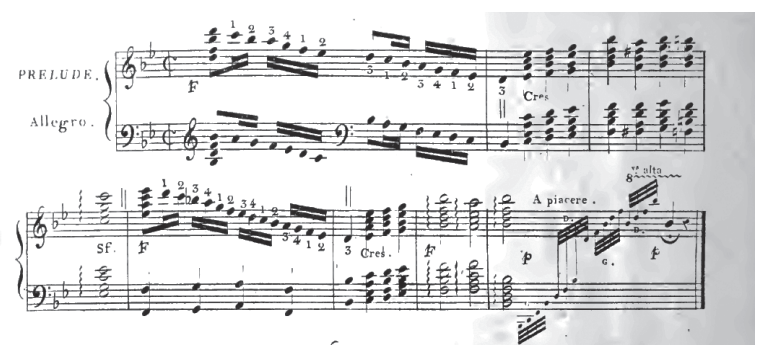

Fig. 3: Prelúdio da Sonatina no.3, opus.92, de François-Joseph Naderman (NADERMAN, c. 1830, p. 14).

Nas três figuras é possível encontrar muito das características dos prelúdios escritos para harpa no século XVIII. Percebe-se o predomínio de arpejos (figuraçóes utilizadas com abundância), mas acordes e escalas também são utilizados. 
Nos prelúdios das figuras 1 e 2 nota-se a ausência de barras de compasso e indicação de andamento, o que reforça a ideia da liberdade rítmica comum nos improvisos. O prelúdio de Naderman (figura 3), sugere andamento rápido e possui barras de compasso, mas provavelmente não deveria ser interpretado com muito rigor rítmico, como sugerem as respiraçóes representadas pelas pequenas barras duplas dos compassos dois, cinco e seis.

$\mathrm{O}$ ato de preludiar persistiu durante um bom tempo entre os harpistas. Durante o início do século XIX o prelúdio parece continuar bem presente na música para harpa.

Segundo Parker (2005, pg.215) "a harpa [...] parece ter se mostrado bastante não usual ao manter os prelúdios como aspecto comum de sua performance".

N. B. Challoner (1784-1851), em seu "A new preceptor for the harp”, método já do início do século XIX, indica (1808, pg.30): "Antes de começar qualquer música na Harpa, é próprio habituar-se a realizar um Prelúdio na tonalidade da peça que será tocada”.

Curiosamente, uma edição inglesa do método de J. B Mayer (?-?) mostrando as vantagens da harpa de pedais de ação-dupla, publicada já em 1820, indica em seu frontispício que reserva parte do livro para explicaçóes sobre princípios de baixo-cifrado que, segundo o próprio editor, são ali colocados para "iniciar os estudantes nos rudimentos da ciência dos acordes, tão indispensavelmente necessária na 'Arte de Preludiar"'.

O desenvolvimento do estilo romântico do século XIX, somado à cada vez maior aceitação da harpa de pedais de ação-dupla como instrumento superior à sua antecessora de pedais de ação-simples e na também nova linguagem que a primeira possibilitou ao instrumento, a "arte de preludiar", na forma como era utilizada anteriormente, mesmo tendo, provavelmente, sobrevivido durante um bom tempo entre os harpistas, foi sendo abandonada e tornou-se praticamente extinta no repertório romântico que viria a dominar o século XIX.

Náo é possível dizer que os intérpretes tenham parado de improvisar música em suas apresentaçóes, mas o costume de se tocar um prelúdio antes de se iniciar qualquer peça realmente caiu em desuso. Os prelúdios escritos, por exemplo, 
são raramente encontrados no repertório da harpa de pedais de ação-dupla.

A transcrição e a adaptação para harpa de peças originalmente compostas para outros instrumentos foi muito provavelmente uma prática comum entre os harpistas nas primeiras décadas desde a invenção da harpa de pedais. Isso pode ter se dado por alguns motivos. Entre eles, o desejo de se executar música de compositores que não houvessem escrito para o instrumento. Outro motivo, e dos mais significativos, talvez tenha sido o de carência de repertório.

A prática da transcrição para harpa sobreviveu até os dias atuais. Do século XVIII até hoje são muitos os exemplos de publicaçóes de arranjos, adaptaçóes e transcrições para harpa de peças originais para cravo, alaúde, piano e até mesmo grupos instrumentais maiores. Se transcrições continuam sendo feitas mesmo em momentos onde a harpa já conta com um repertório mais extenso, é provável que nos primeiros anos do século XVIII, quando a harpa de pedais ainda não possuía repertório próprio e significativo, a execução de transcriçóes tenha sido quase que inevitável aos intérpretes do instrumento.

Naturalmente, a música escrita para instrumentos harmônicos seria a escolha mais óbvia dos harpistas. A harpa, também como um instrumento harmônico capaz de executar harmonias e pelo menos duas linhas musicais ao mesmo tempo, apresentava mais afinidades com a música escrita para alaúde, guitarra, cravo, clavicórdio, pianoforte, etc.

Principalmente os instrumentos de teclado apresentavam algum repertório que poderia ser executado à harpa da maneira como estava escrito, sem necessitar de muitas adaptaçóes. Esse tipo de repertório pode ter sido popular entre os harpistas da época.

No entanto, nem toda música podia ser executada ou facilmente adaptada à harpa de pedais.

Quando vários instrumentos harmônicos executavam, por exemplo, uma mesma linha de baixo contínuo, a execução dificilmente seria idêntica entre um músico e outro. Apesar de estarem seguindo a mesma partitura e tocando, essencialmente, a mesma coisa, cada músico poderia adaptar a linha do contínuo às particularidades de seu instrumento. Como explica Vernillat: "A maioria dos baixos contínuos do século XVIII se realizavam, seja à harpa, seja ao cravo, a partir daqui- 
lo que era lógico à técnica de cada instrumento, observada por seu realizador" (1969, pg.163).

Dessa forma, um músico executaria uma linha de baixo contínuo aplicando a ela características próprias do instrumento com o qual a estivesse executando.

Diferentemente, numa composiçáo pensada para um instrumento específico a situação mostra-se bem diversa. Ao compor para determinado instrumento, o compositor tem em mente um meio para a expressão de sua música e, na maioria das vezes, usufrui das possibilidades desse meio (algo que não acontece sempre na música para harpa, devido à sua associaçáo com o piano). Assim, a execuçáo de uma peça num instrumento diferente para a qual ela foi escrita pode vir a ser algo muito trabalhoso, ineficaz ou até mesmo impossível em certos casos.

Cada instrumento musical é único e apresenta características muito próprias. Portanto, as facilidades e dificuldades técnicas e musicais variam muito de um instrumento para outro. A harpa de pedais de ação-simples, apesar de apresentar algumas possibilidades musicais semelhantes a outros instrumentos harmônicos da época, era um meio de expressão muito diferente dos instrumentos de teclado e de outros instrumentos de cordas dedilhadas.

Além das diferenças técnicas de execução, como, por exemplo, as formas de se tocar acordes, arpejos, escalas e outras figuraçóes muito utilizadas na época (que são algo que influi diretamente nas possibilidades de cada instrumento), a harpa de ação-simples contava ainda com suas limitaçóes harmônicas. Assim, um simples ornamento facilmente executável num cravo, por exemplo, pode se tornar extremamente difícil na harpa e a realizaçâo de uma breve e simples sequência cromática presente numa composição para alaúde torna-se impossível para o harpista.

As incompatibilidades entre a harpa de pedais e um determinado repertório parecem sempre ter ficado claras aos harpistas. Até os dias atuais, mesmo com as maiores possibilidades da harpa de ação-dupla, ainda há um vasto repertório que não apresenta possibilidades de ser executado pelo instrumento em adaptações ou transcrições. Infelizmente para os harpistas, a música de vários dos hoje considerados grandes composi- 
tores acaba sendo "incompatível" com a harpa e, portanto, muito pouco abordada pelos intérpretes do instrumento.

O conhecimento dessas características envolvendo a harpa de pedais torna a leitura de um trecho do Método de Madame de Genlis bastante curiosa. Ainda no primeiro capítulo do documento, a autora faz a seguinte afirmação:

Mas, eu repito, todos as peças de cravo podem ser executadas na Harpa; elas náo oferecem nenhuma dificuldade de dedilhado a um intérprete habilidoso; elas não necessitam, por vezes, de mais do que ligeiras mudanças de uma ou duas notas numa peça, unicamente por conta dos pedais. (GENLIS, 1811, p.4).

No mínimo intrigante, essa afirmação entra em conflito direto com o que foi explanado anteriormente, sobre as impossibilidades de adaptação do instrumento a determinado repertório. Pensando-se que o método de Genlis fora publicado no início do século XIX (e muito provavelmente escrito na mesma época), as pièces de clavecin citadas pela autora envolveriam, a princípio, todo o repertório para o instrumento composto até fins do século XVIII.

Concordando-se ou não com essa afirmação (que pode parecer exagerada do ponto de vista do leitor contemporâneo), a mesma incita algumas especulaçóes.

Madame de Genlis foi, sem dúvida, uma harpista de grande habilidade e isso pode ser deduzido além das suas próprias afirmaçóes de auto-promoção de sua técnica. Afinal, as altas posiçóes de tutora ocupadas pela musicista junto à nobreza francesa mostram que Genlis deveria possuir, de fato, grande conhecimento musical e virtuosismo técnico junto ao instrumento, obtidos através de muita dedicação e estudo. A condessa afirma em seu método (1811, p.2): “[...] um estudo de oito ou nove horas por dia me deu a capacidade, para grande estarrecimento de Gaiffre, de tocar dentro de um ano todas as peças de cravo mais difíceis".

Essa façanha, que, como dito por Genlis, surpreendeu grandemente seu mestre, parece ter sido inédita entre os harpistas da época.

A aproximação da harpista ao repertório dos instrumentos de teclado deu-se aparentemente pela falta de música composta para harpa até aquele momento. Não se sabe se Gaiffre teria lhe sugerido o estudo de peças para teclados ou se a 
aproximação de Genlis a esse repertório havia sido iniciativa própria. De qualquer forma, em seu livro de memórias, a condessa conta:

Como não havia publicado para a harpa nada além de algumas bobagens de autoria de Gaiffre, eu me pus a tocar as peças de cravo, inclusive as mais difíceis, as peças de Mondonville, de Rameau e em seguida de Scarlatti, de Alberti, de Handel, etc. Eu era encorajada pela viva admiração de Gaiffre; eu fazia progressos inconcebíveis; passaram a me ouvir como um fenômeno. (GENLIS, 1878, p.25).

As possibilidades de execução dessas peças encontradas por Madame de Genlis não devem ter se dado apenas por seu talento e longas horas de estudo. Afinal, na segunda metade do século XVIII havia, como mostram consideraçóes da própria Genlis, vários harpistas de grande musicalidade e virtuosismo técnico. No entanto, praticamente nenhum deles é creditado como capaz de executar "todo o repertório" de cravo à harpa.

Essa capacidade de Genlis foi provavelmente desenvolvida também devido a uma questáo técnica bastante original empregada pela condessa: o uso do quinto dedo (já no século XVIII, a grande maioria dos harpistas utilizava a técnica de execução do instrumento mais comum, empregando apenas quatro dedos de cada mão).

Certamente por iniciativa própria, a harpista passa a utilizar o dedo mínimo, da mesma forma como os outros quatro dedos. Em seu método, ela explica (1811, p.2): "Eu exercitava o dedo mínimo da mão direita e conseguia utilizá-lo como os outros dedos, coisa que ficou restrita a mim e a meus alunos".

É claro que o uso do quinto dedo aproximou um pouco mais o modo de se tocar a harpa àquele aplicado aos teclados e logicamente facilitou a execução do repertório dos mesmos. No entanto, apesar de, a princípio, proporcionar melhorias e facilidades de execução à harpa, a técnica envolvendo o quinto dedo não obteve muito sucesso, tendo permanecido, como atesta a própria Genlis, particular a ela e a seus alunos. Entre os motivos que impediram a disseminação dessa técnica estão o fato de que, como atesta France Vernillat (1969, p.174), ao empregar o quinto dedo o harpista era obrigado a mudar a posição das mãos, o que provavelmente provocava mudanças na sonoridade do toque, além de ter de fazer muita força para 
tocar a corda, devido ao fato do quinto dedo ser menor e mais fraco que os outros.

Segundo Parker (2005, p.133), o tipo de instrumento utilizado por Madame de Genlis propiciava maior efetividade de sua técnica. O modelo de harpa francesa utilizada pela condessa possuía menos tensão em suas cordas e um menor espaço entre as mesmas, o que tornava o uso do quinto dedo mais simples e de melhor sonoridade. Já nos novos modelos de harpas surgidas no final do século XVIII, mais parecidos com aquele no qual seriam fabricadas as harpas de ação-dupla, a aplicação da mesma técnica nem sempre era efetiva. Parker ainda considera que em muitas de suas composiçóes Genlis aplica os padróes da técnica de quatro dedos e que o quinto é mais utilizado para se executar peças de teclado sem a necessidade de adaptaçóes.

Nicolas Charles Bochsa (1789-1856), um dos grandes responsáveis pela formação da técnica harpística surgida no século XIX, que é utilizada ainda nos dias atuais, considera o uso do quinto dedo completamente desnecessário e substituível pelo bom emprego da técnica de quatro dedos. Bochsa, que era pertencente a uma nova geração de harpistas, provavelmente não tinha a mesma preocupação de Genlis, e parece ter se dedicado muito mais à execução de peças originais para harpa (inclusive de composiçóes próprias) do que de peças escritas para outros instrumentos.

De qualquer forma, desconsiderando-se as divergentes opinióes sobre o assunto, fica clara a importância da técnica de Madame de Genlis em relação às dificuldades que a mesma conseguiu vencer ao ser capaz de tocar o repertório para teclados.

Entre seus discípulos mais célebres estão Xavier Désargus (1768-1832), harpista que também escreveria um método de harpa com a aplicação da técnica de cinco dedos e Casimir Baecker (1802-1830), pupilo, protegido e filho adotivo de Madame de Genlis que, segundo relatos da época, foi um dos harpistas mais habilidosos de seu tempo, tendo desenvolvido uma técnica que impressionava até mesmo sua própria tutora.

A condessa escreve em seu método vários exemplos do alto virtuosismo técnico atingido por Casimir. Segundo ela (1811, p. 24), o mesmo era capaz de executar na harpa, por exemplo, muitas peças para cravo de Luigi Boccherini (1743-1805), 
entre as quais a grande sonata em ré maior de seu Opus V, utilizando somente os sons harmônicos da harpa, sem mesclá-los aos sons naturais do mesmo. A autora considera que tocar a harpa dessa forma era como "inventar um instrumento completamente novo".

Genlis (1811, p. 34) mostra também um tipo de cadência virtuosística que teria sido executada primeiramente por seu pupilo e que, portanto, recebe o nome de "Cadência de Casimir”. Essa cadência, executada por apenas uma mão do harpista, continha um trilo sustentado pelos dois primeiros dedos (polegar e indicador) enquanto que os outros três realizavam uma melodia, como mostra a figura 4 :

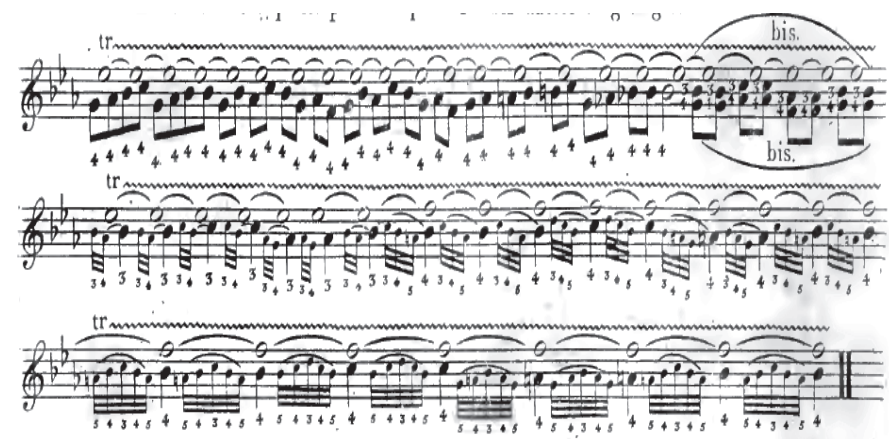

Fig. 4: "Cadência de Casimir" (GENLIS, 1811, p. 34)

A autora (1811, p.23) afirma ainda que Casimir podia executar a mesma cadência com ambas as mãos, exemplificando o seu domínio técnico impressionante. No entanto, mesmo considerando-se todo o virtuosismo instrumental que alguns harpistas poderiam possuir naquela época, é muito provável que a afirmaçáo da condessa de que toda música escrita para cravo poderia ser tocada na harpa seja demasiadamente abrangente e certamente exagerada. Náo se pode excluir o fato de que, provavelmente, a harpista, apesar de possuir grande conhecimento musical, não conhecia toda a música para cravo escrita até então, não só por essa música gerar um repertório imenso mas também pela quantidade de música não editada ou de difícil acesso que poderia ser desconhecida da condessa. Sendo assim, "toda a música para cravo" da qual fala Genlis seria, na verdade, o repertório conhecido pela autora, ou a música à qual a harpista tinha acesso. 
Apesar disso, esse fato não diminui a surpresa e o espanto que as afirmaçóes de Madame de Genlis causam sobre esse assunto em seus leitores. Afinal de contas, tocando ou não tudo o que fosse escrito para cravo na harpa, o nível técnico alcançado pela autora e também por seu protegido deve ter sido realmente impressionante.

Infelizmente, nunca poderemos saber exatamente como soavam as execuçóes desses músicos. Além de parecerem artistas dotados de capacidades muito raras que os tornariam únicos na história, sua técnica não foi disseminada e acabou por extinguir-se com o passar do tempo.

\section{REFERÊNCIAS BIBLIOGRÁFICAS:}

BOCHSA, Nicholas-Charles. A new and improved method of instruction for the harp. London: Chappell \& Co., 1819. Disponível em: <https://ia700603.us.archive.org/11/items/newimprovedmetho01 boch/newimprovedmetho01boch.pdf >. Acesso em 15. jun. 2015.

Nouvelle méthode de harpe, Opus 60. Paris: Dufaut et Dubois, 1830. Disponível em: < https://ia600606.us.archive. org/19/items/imslp-mthode-de-harpe-op60-bochsa-nicholas-charles/PMLP219063-Bochsa_-_Nouvelle_methode_de_harpe. pdf >. Acesso em: 15 jun. 2015.

BORDET, Toussaint. Méthode raisonée pour apprendre la musique. Paris: L'Auteur, 1755. Disponível em: < http://javanese.imslp. info/files/imglnks/usimg/5/56/IMSLP314824-PMLP508545-Bordet_Toussaint_-_M_thode_raisonn_e_pour_apprendre_la_musique_1755_pdf $>$. Acesso em: 15. jun. 2015.

CHALLONER, Neville Butler. A New Preceptor for the Harp. London: Schott \& Co, 1913. Disponível em: <https:// ia600602.us.archive.org/27/items/newpreceptorforh00chal/newpreceptorforh00chal.pdf >. Acesso em: 15 jun. 2015.

COUSINEAU, Jacques-Georges. Méthode de Harpe. 2.ed. Paris: Cousineau Père et Fils, 1803. Disponível em: < http:// conquest.imslp.info/files/imglnks/usimg/e/e9/IMSLP252810-PMLP409682-mthodedeharpeoeu00cous.pdf >. Acesso em: 15 jun. 2015. 
CZERNY, Carl. The Art of Preluding. London: R. Cocks \& Co., 1833. Disponível em: < http://burrito.whatbox.ca:15263/ imglnks/usimg/1/12/IMSLP255178-PMLP251503-CCzerny_ The_Art_of_Preluding_Op.130_BishopEd_bw.pdf >. Acesso em: 15 jun. 2015.

GENLIS, Madame de. Mémoires de Madame de Genlis (en un volume). Paris: Firmin-Didot, 1878. Disponível em: <https:// ia800308.us.archive.org/22/items/mmoiresdemadam00genl/ mmoiresdemadam00genl.pdf >. Acesso em: 15 jun. 2015.

Nouvelle méthode pour apprendre à jouer de la Harpe en moins de six mois de leçons. Paris: Mme. Duhan, 1811. Disponível em: <https://ia700606.us.archive.org/21/items/nouvellemethodep00genl/nouvellemethodep00genl.pdf >. Acesso em: 15 jun. 2015.

HOTTETERRE, Jacques-Martin. L'art de préluder. Paris: Jacques Hotteterre \& Henri Foucault, 1719. Disponível em: < http://burrito.whatbox.ca:15263/imglnks/usimg/4/48/ IMSLP279418-PMLP228362-lart_de_preluder2_hotteterre.pdf >. Acesso em: 15 jun. 2015.

MAYER, John Baptist. A complete demonstration of the advantages afforded by $\mathrm{Mr}$ Sebastian Erard's new invented harp, with double action in the pedals. [London]: [s.n], [18--?]. Disponível em: < http://0035926.netsolhost.com/MorleySheetMusic/500400.pdf >. Acesso em: 15 jun. 2015.

NADERMAN, François Joseph. Sept Sonatines Progressives. Paris: Costallat, [c.1830]. Disponível em: < https://ia700600. us.archive.org/30/items/imslp-sonates-progressives-op92-naderman-franois-joseph/PMLP112393-Naderman_-_7_Sonates_progressives_Op92_Hp_IArch.pdf >. Acesso em: 15 jun. 2015.

PARKER, Mike. Child of Pure Harmony - A source book for the single-action harp. [London], 2005. E-book.

PETRINI, Henri. IIIe. Recueil d'Airs Connus. Paris: L'auteur, 1779. Disponível em: <ftp://ftp.bnf.fr/907/N9078962_PDF_1_-1DM.pdf > . Acesso em 15 jun. 2015. 
RAGUÉ, Louis Charles. L'art de préluder sur la harpe. Paris: Le Duc, 1786.

RENSCH, Roslyn. Harps and Harpists. Bloomington: Indiana University Press, 1989.

VERNILLAT, France. La littérature de la harpe en France au XVIIIe siècle. In: Recherches" sur la Musique françaises classique. Paris: n. 9, 1969, p. 162-185. 